\title{
Editorial What is an education paper?
}

We recently renamed our "education" track's papers from Education Pearl to Education Matters. This would be a good time to explain our vision for the track as a whole, as well as this specific renaming.

Our goal is to provide a venue for people to describe high-quality work related to education. There are many axes that can organize this space. There's the question of topic: educating people about FP, versus educating people about something (including not-FP) using FP. There's the question of method: it could be a short, pithy article, or it could be a detailed exposition. There's the question of evaluation: it could be a quantitative analysis, it could be qualitative, or it might be something that has more of a "you know it when you see it" feel. We want to be open to all of these.

In particular, we would like to see the community move towards papers with richer and deeper evaluation. Too often we have opinions about what works, backed up perhaps by an anecdote or two (the student who told us at the end of the course how much they learned from it). But anecdotes are not evaluation; indeed, the anecdotes could merely hide deep problems that were never investigated. Don't confuse anecdotes with qualitative methods, which have a rich set of tools to get past individual opinion. To put it differently: if we wrote a new compiler and our only justification for why it was better was "Well, it seems to run better, and one of our colleagues said he liked using it", would we accept that paper? A similar standard should apply to education work too. In short, we want to support education research, not only education reports.

However, this is functional programming: we do still value the beautiful little idea with pellucid exposition, the kind that puts a smile on the reader's face. This paper wouldn't need $p$-values or quotes or research questions: that smile says it all. These are Pearls. And we're still open to them. It's just that we're now open to much more, and the term Pearl in the title would both be an inaccurate description of some papers and might dissuade others from even being submitted.

Finally, of course, the new title is a statement. Education Matters. Jeremy Gibbons gets the credit for coming up with that. It's beautiful and taut. It made me laugh. One might almost call it a Pearl.

Shriram Krishnamurthi Computer Science Department, Brown University 